Review Article

\title{
Collaborative Power of Nrf2 and PPAR $\gamma$ Activators against Metabolic and Drug-Induced Oxidative Injury
}

\author{
Choongho Lee \\ College of Pharmacy, Dongguk University, Goyang 10326, Republic of Korea \\ Correspondence should be addressed to Choongho Lee; lkj640@gmail.com
}

Received 6 April 2017; Accepted 25 July 2017; Published 27 August 2017

Academic Editor: M. Yvonne Alexander

Copyright (c) 2017 Choongho Lee. This is an open access article distributed under the Creative Commons Attribution License, which permits unrestricted use, distribution, and reproduction in any medium, provided the original work is properly cited.

\begin{abstract}
Mammalian cells have evolved a unique strategy to protect themselves against oxidative damage induced by reactive oxygen species (ROS). Especially, two transcription factors, nuclear factor erythroid 2p45-related factor 2 (Nrf2) and peroxisome proliferatoractivated receptor $\gamma(\operatorname{PPAR} \gamma)$, have been shown to play key roles in establishing this cellular antioxidative defense system. Recently, several researchers reported ameliorating effects of pharmacological activators for these Nrf2 and PPAR $\gamma$ pathways on the progression of various metabolic disorders and drug-induced organ injuries by oxidative stress. In this review, general features of Nrf2 and PPAR $\gamma$ pathways in the context of oxidative protection will be summarized first. Then, a number of successful applications of natural and synthetic Nrf2 and PPAR $\gamma$ activators to the alleviation of pathological and drug-related oxidative damage will be discussed later.
\end{abstract}

\section{Reactive Oxygen Species and Human Diseases}

Mammalian cells have evolved to utilize oxygen as a final electron acceptor to support their energy metabolism in the mitochondria. As a consequence, they need to deal with a group of unwanted oxygenated byproducts, which are generated during this oxygen-dependent metabolic process. In some cases, environmental stress such as UV or heat exposure also has been attributed to their production. Due to their detrimental nature, these oxygenated byproducts are collectively referred to as highly reactive oxygen species (ROS). Their typical examples include superoxide $\left(\mathrm{O}_{2}^{-}\right)$, hydrogen peroxide $\left(\mathrm{H}_{2} \mathrm{O}_{2}\right)$, hydroxyl radical $\left(\mathrm{OH}^{-}\right)$, and singlet oxygen [1]. A number of cellular metabolic enzymes, such as nicotinamide adenine dinucleotide phosphate (NADPH) oxidase, xanthine oxidase, and nitric oxide synthase (NOS), have been shown to be directly involved in ROS production [2]. Although a certain level of ROS is thought to be necessary for efficient signaling in various cellular pathways [3,4], most of ROS are generally considered to be harmful due to their damaging effects on essential building blocks of cellular metabolism. For this reason, mammalian cells have developed multiple defense systems to work against this ROS- mediated oxidative stress. One of these antioxidative defense mechanisms is to create a highly reducing intracellular environment to neutralize ROS reactivity before their attack to cellular macromolecules [5].

A growing body of evidence strongly suggests an etiological role of oxidative stress-associated inflammation and cell death in the development of many human diseases [6-11]. Especially, oxidative damage has been intimately linked with the pathogenesis of several chronic metabolic disorders such diabetes, atherosclerosis, and hypercholesterolemia [12-14]. In addition, insufficient cellular protection against oxidative stress also has been ascribed as another contributing factor for developing various liver, kidney, brain, and skin diseases [15-17]. On top of this, oxidative stress was even demonstrated to play a major role in exhibiting many clinically relevant side effects of various pharmacological agents. Therefore, efficient reduction of oxidative stress through activation of multiple antioxidative defense systems was envisaged as a promising strategy to improve a wide range of ROS-induced pathological conditions. Recently, several research groups have published a series of encouraging data suggesting effectiveness of combined use of pharmacological activators for two critical antioxidative pathways. They 


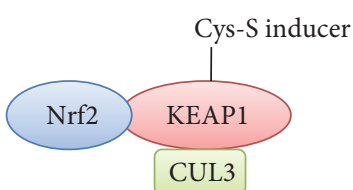

Inhibition of Nrf2
degradation

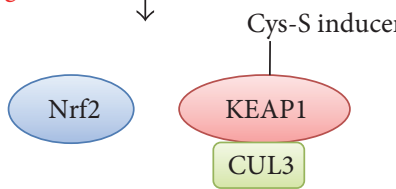

Nuclear
translocation

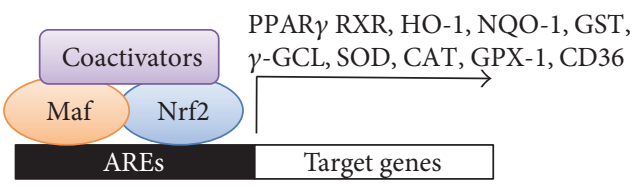

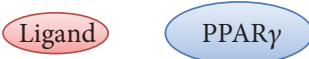

Ligand binding

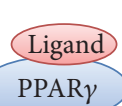

$\operatorname{PPAR} \gamma$

Nuclear
$\downarrow$

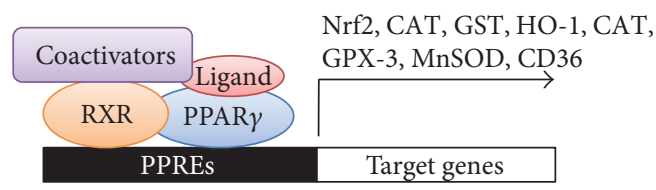

Collaborative antioxidative action!

Figure 1: Crosstalk between Nrf2 and PPAR $\gamma$ pathways against oxidative stress. Abbreviations used within the figure are as follows. Nrf2; nuclear factor erythroid 2-related factor 2, KEAP1; Kelch-like ECH-associated protein 1, CUL3; cullin3, PPAR $\gamma$; peroxisome proliferatoractivated receptor $\gamma$, HO-1; heme oxygenase-1, NQO-1; NAD $(\mathrm{P}) \mathrm{H}$ quinone oxidoreductase-1, GST; glutathione, $\gamma$-GCL; $\gamma$-glutamyl cysteine ligase, SOD; superoxide dismutase, CAT; catalase, GPX; glutathione peroxidase, AREs; anti-oxidant response elements, MnSOD; manganese superoxide dismutase, PPREs; PPAR response element, RXR; retinoid X receptor.

involve two nuclear transcription factors, which are nuclear factor erythroid 2p45-related factor 2 (Nrf2) and peroxisome proliferator-activated receptor $\gamma(\operatorname{PPAR} \gamma)$. Stimulation of these two antioxidative pathways by various pharmacological agents turned out to be extremely beneficial for alleviating a variety of ROS-induced metabolic disorders and drug-induced injuries. In this review, general characteristics of Nrf2 and PPAR $\gamma$ pathways in the context of oxidative protection will be summarized first. Then, a number of successful applications of combined or separate use of Nrf2 and PPAR $\gamma$ activators for amelioration of pathological and drug-induced oxidative injuries will be discussed later.

\section{Nrf2 Pathway against Oxidative Stress}

Nrf2 is by far the best characterized transcription factor with an oxidant/electrophile-sensing capability [18]. It is a basic leucine zipper protein with six conserved Nrf2-ECH homology (Neh) domains [5]. Especially, ETGE and DLG motifs located in the second Neh2 domain were shown to play a critical role in its complex formation with another essential component of this pathway, Kelch-like ECH-associated protein 1 (KEAP1) [19]. This Nrf2/KEAP1 complex formation was demonstrated to be necessary for restraining the transcriptional activity of Nrf2 [20]. In regard to its sensing mechanism, KEAP1 acts as a main sensor molecule for oxidative stress in this pathway. It is an adaptor protein for cullin-3-based E3 ubiquitin ligase complex. Redox-sensitive twenty-five cysteine residues of KEAP1 in its linker region function as essential determinants for regulating its ubiquitin ligase activity [21]. Conjugation of a variety of ROS-inducing agents with these cysteine residues leads to inhibition of KEAP1-mediated ubiquitination [22], resulting in stabilization and nuclear translocation of Nrf2. Once transported inside the nucleus, Nrf2 associates with one of small Maf proteins and other coactivators to form a trimetric protein complex. Then, this complex binds to the antioxidant response elements (AREs) in the upstream promoter regions of many cytoprotective and detoxifying genes for their transcriptional activation (Figure 1). Typical examples of Nrf2-regulated genes include $\gamma$-glutamyl cysteine ligase $(\gamma$-GCL), NAD(P)H quinone oxidoreductase-1 (NQO-1), glutathione S-transferase (GST), heme oxygenase-1 (HO-1), uridine diphosphate (UDP) glucuronosyl transferase, superoxide dismutase (SOD), catalase (CAT), and glutathione peroxidase-1 (GPX-1) [5, 23-28]. In addition to this KEAP1-dependent mechanism, Nrf2 has been reported to be regulated via a number of KEAP1-independent mechanisms. They include transcriptional activation of Nrf2 gene through aryl hydrocarbon receptor (AHR) and its nuclear translocator (ARNT) binding to xenobiotic response element (XRE) [29], transcriptional activation of Nrf2 target genes through association of NF- $\kappa \mathrm{B}$ with $\mathrm{ARE}$, post transcriptional regulation of Nrf2 mRNA with host microRNAs [30, 31], post translational modification of $\mathrm{Nrf} 2$ 
protein by phosphorylation [32, 33], acetylation [34, 35], and ubiquitination [36], and association of $\mathrm{Nrf} 2$ protein with novel binding partners $[37,38]$. This seemingly complicated transcriptional, epigenetic, and posttranslational control of Nrf2 seems to be designed to fine-tune its antioxidative activity upon redox perturbation in order to minimize damaging effects of oxidative stress on cellular metabolism [39].

\section{PPAR $\gamma$ Pathway against Oxidative Stress}

PPARs are the members of a subfamily of the nuclear receptors and transcription factors. In general, they are involved in the regulation of a wide range of cellular processes such as differentiation, development, metabolism, and even oncogenesis [40-43]. Originally, peroxisome proliferators were found as genotoxic rodent carcinogens due to their proliferative effects on peroxisomes in rats $[2,44$, 45]. Interestingly, their peroxisome proliferative activity turned out to be due to their oxidative DNA damage, which was caused by leakage of $\mathrm{H}_{2} \mathrm{O}_{2}$ from peroxisomes [44]. PPAR family genes comprise of three isoforms including $\operatorname{PPAR} \alpha, \operatorname{PPAR} \beta / \delta$, and $\operatorname{PPAR} \gamma$ [46]. All three subtypes of this PPAR subfamily were found to be highly expressed in mammalian tissues, which were necessary for energy homeostasis [47]. In regard to their signaling mechanisms, once ligand-bound PPARs enter the nucleus, they form a heterodimer with the retinoid $\mathrm{X}$ receptor (RXR). Then, they bind to specific PPAR response elements (PPREs) within the promoter region of PPAR-regulated genes [48-50]. Depending on isoforms of PPARs, this PPAR/RXR heterodimer recruits a large protein complex of coactivators to activate the transcription of different sets of PPAR target genes, ultimately leading to a unique physiological outcome (Figure 1) [45].

From the pharmacological point of view, PPAR $\gamma$ has been most extensively characterized as an antidiabetic target $[45,51]$. For this reason, it is often called "a glitazone receptor." In general, PPAR $\gamma$ modulates fatty acid storage and glucose metabolism through stimulation of lipid uptake and adipogenesis by PPAR $\gamma$-regulated gene expression in fat cells [51]. This was supported by an observation of very limited generation of adipose tissue in PPAR $\gamma$ knockout mice [52]. In addition, PPAR $\gamma$ also has been responsible for pathogenesis of several metabolic and vascular diseases including obesity, diabetes, and atherosclerosis [53-55]. Thanks to their regulatory roles in lipid and carbohydrate metabolism, $\operatorname{PPAR} \gamma$ agonists have been widely used in the treatment of hyperlipidemia and hyperglycemia [56, 57]. Although PPAR $\gamma$ was initially regarded as a master regulator of transcription in adipogenesis [58], it was also shown to play additional roles in other biologically relevant processes such as infection and inflammation. In particular, many literatures identified PPAR $\gamma$ as a negative regulator of oxidative stressinduced inflammation under either infectious or pathological conditions [51, 59]. Detailed mechanistic studies also revealed that PPAR $\gamma$ was indeed able to suppress inflammation by transcriptional repression of many well-characterized proinflammatory transcription factors and enzymes such as nuclear factor kappa B (NF- $\kappa \mathrm{B})$, signal transducer and activator of trancription-6 (STAT-6), and activator protein 1 (AP-1), cyclooxygenase-2 (COX-2), and induced nitric oxide synthase (iNOS) [2, 48, 60-62]. Antioxidative function of $\operatorname{PPAR} \gamma$ was also reported to be mediated by transcriptional activation of a number of several antioxidant genes such as HO-1, CAT, GPX-3, and manganese superoxide dismutase (MnSOD) through its direct association with PPREs of their promoter regions $[48,49,63]$. For this reason, PPAR $\gamma$ has emerged as a new target for anti-inflammatory and antioxidative pharmacotherapy in many diseases, which are adversely affected by oxidative stress and subsequent inflammation [48, 51, 59].

\section{Crosstalk between Nrf2 and PPAR $\gamma$ Pathways against Oxidative Stress}

Several studies have strongly suggested existence of reciprocal regulation of Nrf2 and PPAR $\gamma$ pathways to reinforce the expression of one another $[48,61,64]$. In this sense, Nrf2 and PPAR $\gamma$ pathways seem to be connected by a positive feedback loop, which maintains the expression of both transcription factors and their target antioxidant genes in a simultaneous manner. Then, what are known about molecular mechanisms for PPAR $\gamma$ regulation by Nrf2? Huang et al. provided insight into this question by identifying PPAR $\gamma$ as a direct target gene induced by Nrf2 transcriptional activation [64]. In line with this finding, several other researchers also reported direct binding of Nrf2 to newly identified AREs in the regions of the PPAR $\gamma$ promoter by using gel shift and coimmunoprecipitation assays (Figure 1) $[48,61,64,65]$. In their studies, ARE sequences located at -784/-764 and -916 regions of the PPAR $\gamma$ promoter were found to be necessary for Nrf2-regulated PPAR $\gamma$ expression. As supporting evidence to this direct regulation of PPAR $\gamma$ by $\mathrm{Nrf} 2$ in vivo, PPAR $\gamma$ expression was also found to be markedly lower in Nrf2 knockout mice [64]. Other two studies also reported severely compromised expression of PPAR $\gamma$ in Nrf2 null mice and significantly reduced basal levels of PPAR $\gamma$ by Nrf2 deletion [48, 61]. Then, what is the biological significance of this positive regulation of PPAR $\gamma$ by Nrf2? It was found that Nrf2-regulated PPAR $\gamma$ expression was required for protection against acute lung injury in mice [65]. In this report, $\operatorname{PPAR} \gamma$ induction was found to be suppressed in Nrf2-deficient mice in hyperoxia-susceptible manner [65]. This piece of evidence strongly suggests the requirement of positive induction of PAPR $\gamma$ by Nrf 2 for the amelioration of acute lung injury induced by hyperoxia. In addition, $\mathrm{RXR}$, another critical component of PPAR $\gamma$ pathway, also turned out to be induced by activation of $\mathrm{Nrf} 2$ pathway by using chromatin immunoprecipitation and sequencing experiments [66]. These data further imply the presence of another layer of positive regulation of PPAR $\gamma$ pathway by Nrf2 (Figure 1).

Then, what is known about the opposite pattern of regulation, which is the PPAR $\gamma$ action on Nrf2 pathway? So far, several lines of evidence have raised the possibility of direct involvement of PPAR $\gamma$ in the activation of $\mathrm{Nrf} 2$ pathway. Chorley et al. found that PPAR $\gamma$ agonists were able to induce 
transcription of a set of antioxidative defense genes such as GST, HO-1, and CD36 (Figure 1) [66]. Since these PPAR $\gamma$ regulated genes belong to a group of Nrf2-regulated genes, this observation strongly suggests direct regulation of Nrf2 pathway by PPAR $\gamma$. In support of this hypothesis, expression of Nrf2 was also shown to be reduced by knockdown of PPAR $\gamma$ in a mouse model [39]. Kvandova et al. even reported the presence of putative PPREs in the promoter regions of Nrf2 gene [2] (Figure 1). This finding further implies possibility of direct binding of PPAR $\gamma$ on Nrf2 promoter for positive regulation of Nrf2 pathway. On the other hand, collaborative action of both Nrf2 and PPAR $\gamma$ transcription factors on a single target gene also seems to be plausible since GST promoter was found to possess both ARE and PPRE sequences to allow for simultaneous stimulation of its transcription [2]. Therefore, concurrent activation of both Nrf2 and PPAR $\gamma$ pathways by different combinations of pharmacological agonists seems to be possible to achieve the maximum levels of antioxidative state for full protection against the harmful effects of ROS (Figure 1).

\section{Pharmacological Targeting of Nrf2 and PPAR $\gamma$ Pathways}

Many endeavors to pharmacologically manipulate Nrf2 and PPAR $\gamma$ pathways have been shown to be successful in different kinds of in vitro as well as in vivo disease models. In order to take full advantage of the collaborative action of these two critical antioxidant pathways for alleviation of ROS-induced damages in various metabolic diseases and drug-induced injury, many researchers have tried to apply several Nrf2 and PPAR $\gamma$ activators to various disease models. So far, several metabolic diseases including atherosclerosis, diabetes mellitus, and hepatic and renal diseases have been studied in order to test any beneficial effects of these Nrf2 and PPAR $\gamma$ activators on their disease progression. From now on, therapeutic efficacies and toxicities of various Nrf2 and PPAR $\gamma$ activators studied in these metabolic disorders and some drug-induced organ injuries will be summarized first (Table 1). In order to describe Nrf2 and PPAR $\gamma$ activators in a more systematic manner, they were categorized as Nrf2 activator, PPAR $\gamma$ activators, and dual Nrf2 and PPAR $\gamma$ activators based on their target specificities. Additionally, PPAR $\gamma$ activators were further classified as endogenous, synthetic, and natural PPAR $\gamma$ activators based on their origins of synthesis.

\subsection{Nrf2 Activator}

5.1.1. Bardoxolone Methyl. Bardoxolone methyl (BARD) is an orally available semisynthetic triterpenoid [67]. Its chemical structure is based on the scaffold of oleanolic acid, a naturally occurring pentacyclic triterpenoid. According to preclinical studies, BARD was shown to activate Nrf2 pathway for its antioxidant effect. It was also reported to inhibit $\mathrm{NF}-\kappa \mathrm{B}$ pathway for its anti-inflammatory effect [68]. Wu et al. found that BARD was able to ameliorate ischemic acute kidney injury (AKI) through increased expression of Nrf2, $\operatorname{PPAR} \gamma$, and HO-1 in the mouse model [69]. In this study,
BARD was able to exert its positive effect on $\operatorname{PPAR} \gamma$ pathway by enhancing the amount of PPAR $\gamma$ mRNA and protein [69]. In regard to its mechanism of action, they found that BARD was able to transcriptionally activate HO-1 gene during ischemic AKI via Nrf2-independent manner. This finding suggests that direct upregulation of HO-1 by PPAR $\gamma$ could be the main mechanism of action for the reduction of AKI by BARD. In spite of its impressive antioxidant activity, BARD failed to pass the third phase clinical trial for the treatment of chronic kidney disease due to a higher rate of heart-related adverse events, including heart failure, hospitalizations, and deaths [70].

5.1.2. Curcumin. Curcumin is a bright yellow plant-derived chemical used as a food additive and supplement. It is a well-known natural Nrf2 activator [71]. Olagnier et al. discovered that several Nrf2 activators were able to upregulate one of scavenger receptors, CD36, leading to the stimulation of phagocytosis of Plasmodium falciparum, a causative pathogen for malaria, on human monocyte-derived macrophages in inflammatory conditions [72]. In accordance with this finding, curcumin was also able to increase phagocytosis of Plasmodium falciparum through upregulation of CD36 surface expression on monocytes/macrophages [73]. In this study, seven putative AREs were identified in the promoter region of CD36 gene, which explained mode of the transcriptional activation of CD36 gene by curcumin. Inhibition of curcumin-induced Nrf2 protein expression by a general antioxidant molecule, $\mathrm{N}$-acetyl cysteine treatment, resulted in the loss of upregulation of CD36 by curcumin. This further suggested direct involvement of ROS in the activation of Nrf2 pathway by curcumin [73]. Interestingly, curcumin was also able to increase the expression of PPAR $\gamma$ at transcriptional and translational level [73]. This implies that simultaneous activation of both Nrf2 and PPAR $\gamma$ pathways by curcumin may play a role in upregulation of CD36, which can lead to increased phagocytosis of Plasmodium falciparum by macrophages.

\subsection{Endogenous PPAR $\gamma$ Activators}

5.2.1. 15-Deoxy- 12 , 14-Prostaglandin J2. 15-Deoxy- $\Delta 12,14$ prostaglandin J2 (15d-PGJ2) is an electrophilic cyclopentene prostaglandin. It was shown to act as an endogenous ligand for PPAR $\gamma[74,75]$. Its highly reactive $\alpha, \beta$-unsaturated carbonyl groups were shown to readily interact and make a covalent bonding with cysteine thiol groups in the ligandbinding domain of PPAR $\gamma$ [74]. 15d-PGJ2 was also demonstrated to be able to increase Nrf2 expression via a PPAR $\gamma$ dependent manner [48]. Interestingly, cysteines of the linker region of KEAP1 were also shown to be engaged in direct binding of 15d-PGJ2 to KEAP1 [74]. In regard to mechanism for its antioxidative activity, 15d-PGJ2 was shown to protect neurons from homocysteic acid-induced oxidative death via Nrf2-dependent and PPAR $\gamma$-independent mechanisms [75]. In this study, Nrf2 knockdown in astrocytes abrogated 15d-PGJ2's neuroprotective effect. Under this Nrf2 knockdown condition, 15d-PGJ2 was not able to facilitate induction of Nrf2 target genes. In contrast, knockdown of the 


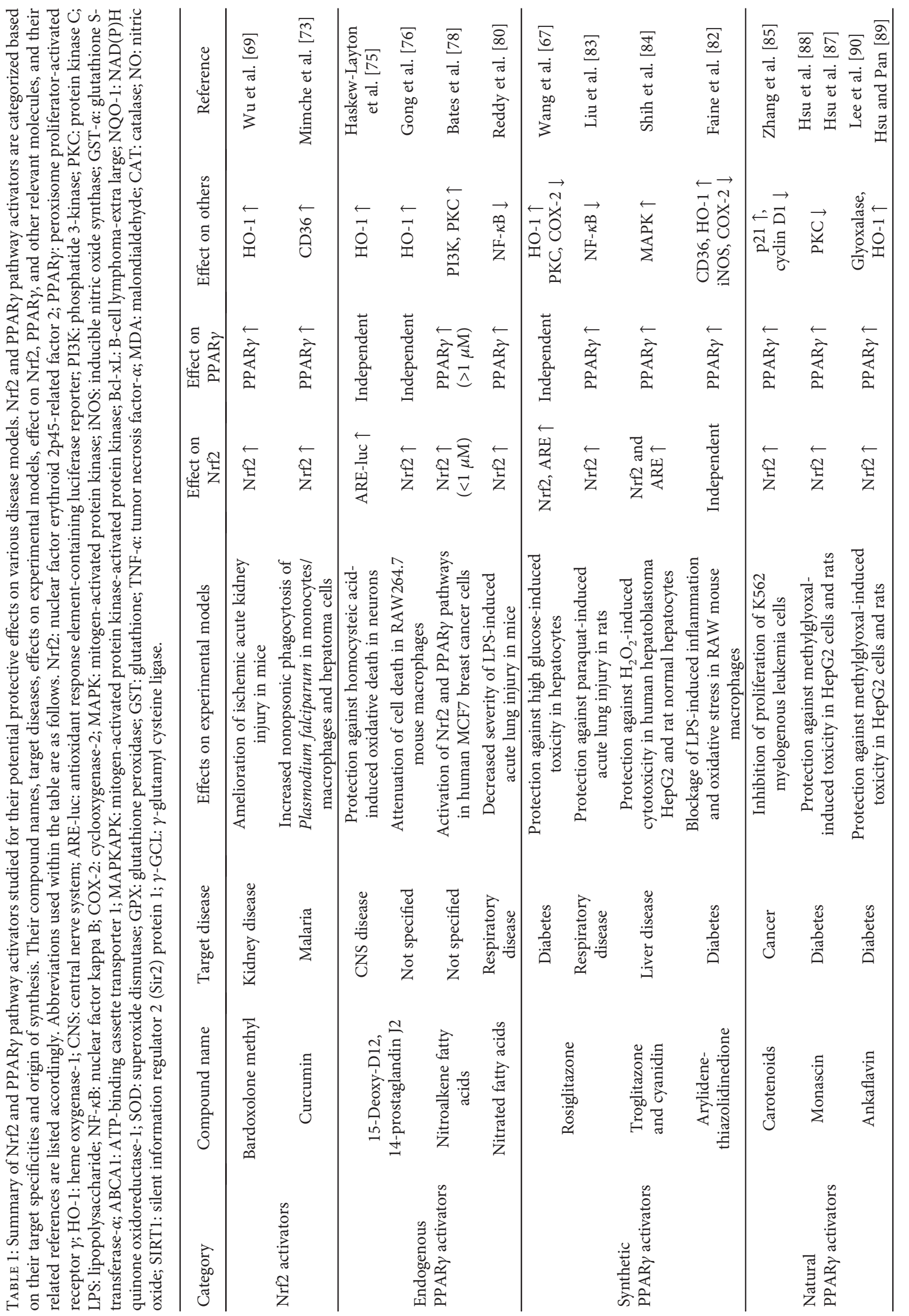




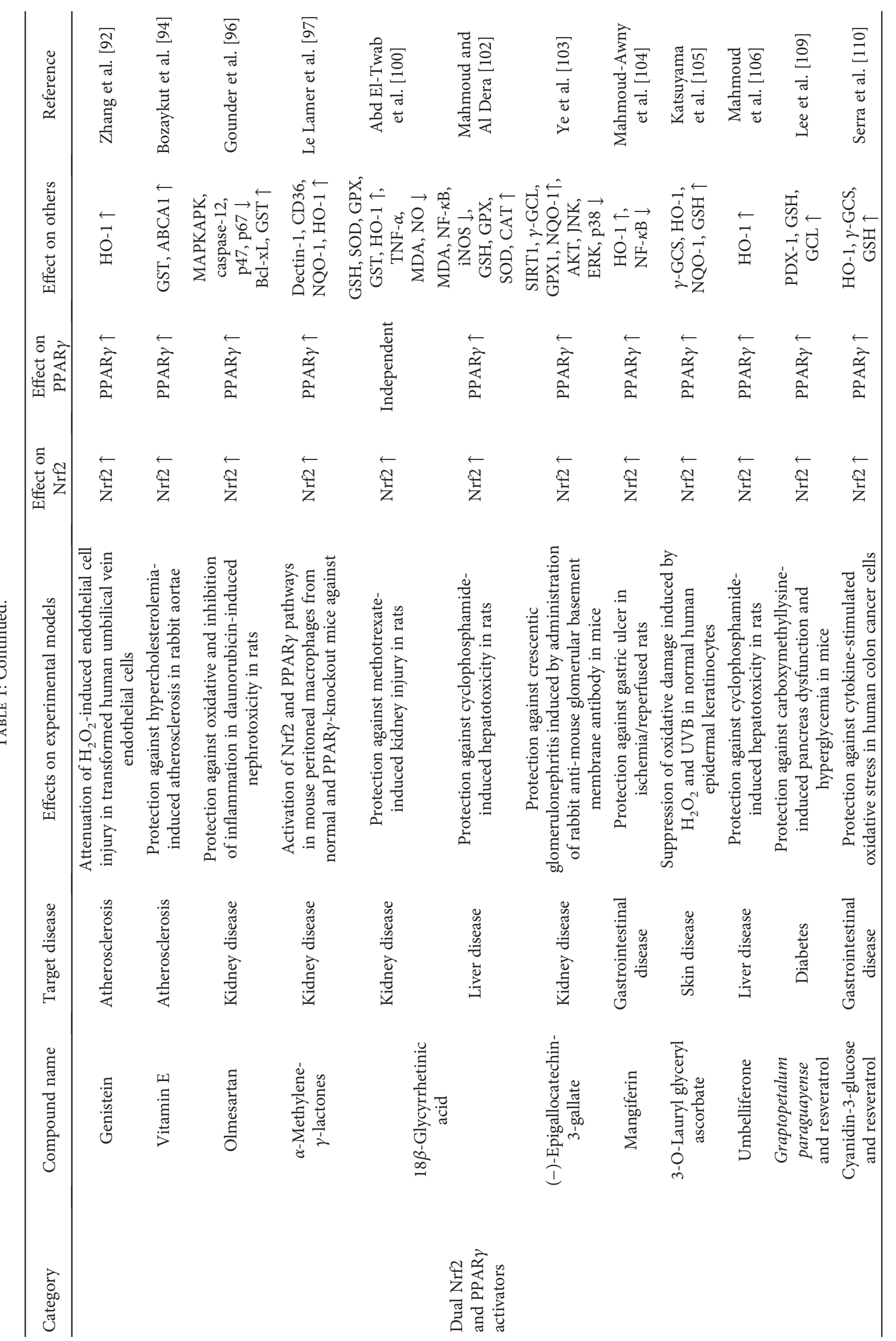


PPAR $\gamma$ did not alter the neuroprotective activity of $15 \mathrm{~d}-$ PGJ2 [75]. Among many Nrf2-regulated genes, HO-1 turned out to play the most critical role in mediating the antioxidative effect of 15d-PGJ2 [75]. Gong et al. also reported protective activity of $15 \mathrm{~d}-\mathrm{PGJ} 2$ against oxidative stress in RAW264.7 mouse macrophages. In this study, they showed that attenuation of cell death by $15 \mathrm{~d}-\mathrm{PGJ} 2$ was due to its positive induction of the mouse HO-1 gene [76]. More specifically, they found that 15d-PGJ2-induced stabilization of Nrf2 was able to mediate transcriptional activation of the mouse HO-1 through Nrf2 binding on its enhancer region. However, this induction of mouse HO-1 expression by 15d-PGJ2 again turned out to be independent of PPAR $\gamma$ pathway [76].

5.2.2. Nitroalkene Fatty Acids. Nitroalkene fatty acids (NAs) are naturally occurring electrophilic derivatives of unsaturated fatty acids. NAs are formed via nitric oxidedependent oxidative reactions [77]. Bates et al. found that NAs were able to form direct adduct with KEAP1, leading to the activation of Nrf2 pathway. In this report, they reported that NAs were able to display differential transactivation activities toward Nrf2 and PPAR $\gamma$ pathways in a dosedependent manner [78]. Briefly, activation of $\operatorname{PPAR} \gamma$ pathway occurred at nanomolar concentrations of NAs in MCF7 breast cancer cells. However, activation of Nrf2 pathway occurred at much higher concentrations of NAs ( $\geq 3 \mu \mathrm{M})$ [78]. Based on these results, they concluded that direct activation of PPAR $\gamma$ transcription by NAs would dominate over their electrophilic activation of Nrf2 during antioxidant/protective responses [78]. Of note, both phosphatide 3-kinase (PI3K) and protein kinase $\mathrm{C}(\mathrm{PKC})$ activations were also shown to be required for transcriptional activation of Nrf2 and PPAR $\gamma$ pathways by NAs in this study [78].

5.2.3. Nitrated Fatty Acids. Endogenous nitrated fatty acids (NFAs) are produced by nonenzymatic reaction of nitric oxide or its inorganic reaction products with naturally present unsaturated fatty acids [79]. NFAs can act as activating ligands for all three PPARs, particularly with the greatest potency as PPAR $\gamma$ agonists [80]. Reddy et al. found that a nitro-oleic acid, one of the most potent NFAs, was able to diminish severity of lipopolysaccharide- (LPS-) induced acute lung injury in mice [80]. In regard to its mechanism of action, they found that its protective effect against LPSinduced inflammation was mediated by increased transcriptional activity of PPAR $\gamma$. They also showed that this upregulation of PPAR $\gamma$ by a nitro-oleic acid led to subsequent induction of $\mathrm{Nrf} 2$ and decreased transcription of the proinflammatory gene, NF- $\kappa \mathrm{B}[80]$.

5.3. Synthetic PPAR $\gamma$ Activators. Thiazolidinedione (TZDs) drugs are cognate ligands for PPAR $\gamma$. They are frequently used for the treatment of type 2 diabetes [45, 49]. TZDs drugs are known to facilitate insulin-mediated adipocyte differentiation by counteracting the negative effects of inflammatory cytokines [81]. In general, TZDs drug treatment was shown to decrease ROS production in vascular smooth muscle cells [2]. Effects of three kinds of synthetic PPAR $\gamma$ activators on oxidative stress-induced disease models have been examined so far [50, 82-84]. They include rosiglitazone (RSG), troglitazone (TG) in combination with cyanidin, and arylidenethiazolidinedione. Here, their activities against oxidative stress and mechanisms of action for these antioxidative activities will be discussed briefly.

5.3.1. Rosiglitazone. RSG is a member of the TDZs family and a ligand for the PPAR $\gamma$. Wang et al. found that RSG was able to protect hepatocytes from high glucose-induced toxicity via both PPAR $\gamma$-dependent and PPAR $\gamma$-independent manners [50]. In this study, they found that RSG increased the expression of Nrf2 and HO- 1 in a PPAR $\gamma$-dependent manner, leading to the elimination of excessive ROS [50]. In addition, they also found that the inhibitory effect of RSG on ROS generation was related with PKC inactivation. In line with this positive role of RSG in reduction of oxidative stress, Liu et al. also reported that RSG was able to inhibit paraquat- (PQ-) induced acute lung injury in rats [83]. In this study, they found that protection of rats against PQ-induced acute lung injury by RSG was mediated by activating both Nrf2 and PPAR $\gamma$ pathways. They also showed that inhibition of NF$\kappa \mathrm{B}$ activation by RSG was required for the alleviation of PQ-induced acute lung injury [83].

5.3.2. Troglitazone with Cyanidin. Cyanidin is a natural organic pigment found in many red berries. Shih et al. reported that cyanidin in combination with TG was able to prevent $\mathrm{H}_{2} \mathrm{O}_{2}$-induced cytotoxicity in human hepatoblastoma HepG2 and rat normal hepatocyte cells [84]. In this study, they found that antioxidative activities of cyaniding and TG were mediated through activation of mitogenactivated protein kinase (MAPK) and Nrf2 pathways [84]. They also reported that cotreatment of cyanidin and TG was able to transcriptionally upregulate expression of antioxidant and detoxifying genes through activation of AREmediated Nrf2 pathway [84]. Based on these results, they suggested simultaneous administration of cyanidin and PPAR $\gamma$ agonists to reverse the metabolic dysfunctionrelated oxidative damage [84].

5.3.3. Arylidene-Thiazolidinedione. Fair amount of efforts has been devoted to the modification of chemical structures of TZDs in order to reduce their endogenous side effects such as water retention, weight gain, and eyesight problems. Faine et al. found that one of their chemically modified TZDs, the arylidene-thiazolidinedione 5-(4-methanesulfonyl-benzylidene)-3-(4-nitrobenzyl)-thiazolidine-2,4-dione (SF23), possessed a weaker affinity for PPAR $\gamma$ [82]. However, SF23 turned out to have impressive anti-inflammatory and antioxidant properties, which were evidenced by efficient blockage of LPS-induced inflammation and oxidative stress in RAW 267.4 macrophages [82]. SF23 was also able to enhance the mRNA expression of CD36 and suppress the mRNA expression of both iNOS and COX-2. They also reported that SF23 was able to display better antioxidant effects on the LPSstimulated macrophages than RSG. Interestingly, this antioxidant activity of SF23 was shown to be exerted via an Nrf2independent manner [82]. 


\subsection{Natural PPAR $\gamma$ Activators}

5.4.1. Carotenoids. Carotenoids are organic plant pigments with a tetraterpenoid structure. Zhang et al. found that carotenoids were able to inhibit proliferation of K562 cancer cells through induction of cell apoptosis and blockage of cycle progression [85]. Especially, this carotenoid-induced cell cycle arrest was shown to be mediated by increased expression of a cell cycle blocker, p21, and decreased expression of cyclin D1. This antiproliferative effect of carotenoids was shown to be dependent on upregulation of both Nrf2 and PPAR $\gamma$ expression [85]. Based on these results, they concluded that $\mathrm{Nrf} 2$ and PPAR $\gamma$ pathways could be activated in order to induce the growth inhibitory effects on cancer cells [85].

5.4.2. Monascin. Monascin is a natural compound obtained from Monascus-fermented products. Beisswenger found that monascin was able to attenuate the hyperglycemic toxicity induced by methylglyoxal (MG). MG is a major precursor of advanced glycation end products, which were well known for their diabetes-inducing activities through impairment of an insulin transcription factor, pancreatic and duodenal homeobox-1 (PDX-1) [86]. The protective activity of monascin against MG-induced diabetes was shown to be mediated through positive modulation of both Nrf2 and PPAR $\gamma$ pathways [87]. In this report, Hsu et al. identified monascin as novel natural Nrf2 and PPAR $\gamma$ agonists by using Nrf2 and PPAR $\gamma$ promoter reporter assays in HepG2 cells. Activation of Nrf2 pathway by monascin also resulted in downregulation of hyperinsulinemia in an oral glucose tolerance test [87]. In their related studies, they also reported that cotreatment of monascin with another Nrf2 activator, allyl isothiocyanate, was able to attenuate MG-Induced PPAR $\gamma$ phosphorylation and degradation through inhibition of the oxidative stress via a PKC-dependent manner [88].

5.4.3. Ankaflavin. Ankaflavin (AK) is a natural pigment isolated from Monascus-fermented products. It was found to possess the PPAR $\gamma$ agonist activity [89]. Lee et al. reported that $\mathrm{AK}$ was able to upregulate $\mathrm{Nrf} 2$ pathway to attenuate MG-induced diabetes in vivo [90]. Although AK failed to alter hepatic Nrf2 mRNA or protein expression, it significantly increased Nrf2 phosphorylation at serine 40 . This led to increased transcriptional activation of $\mathrm{HO}-1$ gene. They also found that protective effects of $\mathrm{AK}$ against diabetes were mediated by the upregulation of Nrf2 pathway, resulting in induction of glyoxalase and HO-1 $[89,90]$. In addition, AK also was able to increase Maf-A and PDX-1 expression through activation of PPAR $\gamma$ pathway. They suggested that this could be one potential mechanism for elevating pancreatic insulin synthesis and improving hyperglycemia by $\mathrm{AK}$ in MG-treated rats [89].

\subsection{Dual Nrf2 and PPARY Activators}

5.5.1. Genistein. Genistein is a primary isoflavone from soybeans [91]. Zhang et al. found that genistein was able to induce activation of both $\mathrm{Nrf} 2$ and PPAR $\gamma$ pathways and that this led to attenuation of $\mathrm{H}_{2} \mathrm{O}_{2}$-induced cell injury in transformed human umbilical vein endothelial cells [92]. In this report, dual activation of Nrf2 and PPAR $\gamma$ pathways by genistein was demonstrated by enhanced promoter activity of both Nrf2 and PPAR $\gamma$ reporters by genistein [92]. In regard to its mechanism of action, induction of $\mathrm{HO}-1$ by genistein seemed to mediate its protective effect against oxidative stress [92].

5.5.2. Vitamin E. Vitamin $\mathrm{E}$ is a group of compounds including both tocopherols and tocotrienols. Their antioxidant activities have been extensively characterized by many researchers [93]. Bozaykut et al. reported that vitamin E was able to afford protection against hypercholesterolemiainduced atherosclerosis in the rabbit aorta model. In this study, they found that vitamin E was able to show this protective effect through decreased expression of matrix metalloproteinase-1 (MMP-1) and increased expression of PPAR $\gamma$, GST- $\alpha$, and ATP-binding cassette transporter 1 (ABCA1) in the aortae of cholesterol-fed rabbits [94]. Protein expression of Nrf2 was also increased in both the cholesterolfed and the vitamin E-supplemented groups. Vitamin E appeared to afford this protection through activation of both Nrf2 and PPAR $\gamma$ pathways, resulting in induction of several antioxidant genes [94].

5.5.3. Olmesartan. Daunorubicin is a chemotherapeutic medication used to treat various kinds of cancer. Oxidative injury has been suspected to play a major role for daunorubicin in inducing chronic nephrotoxicity [95]. Gounder et al. found that olmesartan, an angiotensin II receptor antagonist, which was used for the treatment of high blood pressure, was able to protect against this daunorubicin-induced nephrotoxicity in rats [96]. In this study, they found that olmesartan treatment downregulated phosphorylation of several key signaling molecules such as mitogen-activated protein kinase-activated protein kinase (MAPKAPK), caspase-12, p47, and p67. Olmesartan was also able to upregulate renal expression of PPAR $\gamma, B$-cell lymphoma-extra large (Bcl-xL), GPX, and Nrf2 [96]. Based on these results, they concluded that positive regulation of both Nrf2 and PPAR $\gamma$ pathways seemed to mediate protective effects of olmesartan against daunorubicin-induced nephrotoxicity.

5.5.4. $\alpha$-Methylene- $\gamma$-Lactones. Protolichesterinic acid is a lichen paraconic acid with an $\alpha, \beta$-unsaturated lactone moiety. Le Lamer et al. found that protolichesterinic acid derivatives, $\alpha$-methylene- $\gamma$-lactones, were able to induce expression of Nrf2 target genes such as NQO-1 and HO-1 and PPAR $\gamma$ target genes such as Dectin-1 and CD36 in macrophages. Based on these results, they concluded that $\alpha$-methylene- $\gamma$-lactones were potent dual activators of both Nrf2 and PPAR $\gamma$ pathways [97]. In regard to more detailed mechanism of action for activation of PPAR $\gamma$ pathway by $\alpha$-methylene- $\gamma$-lactones, they suggested that $\alpha$-methylene- $\gamma$-lactones may act as covalent ligands through a Michael addition with a cysteine residue in the PPAR $\gamma$ ligand-binding domain [97].

5.5.5. 18ß-Glycyrrhetinic Acid. Methotrexate (MTX) is a dihydrofolate reductase inhibitor used for several human 
malignancies and autoimmune disorders. Due to its prooxidant and nonspecific action, MTX has been reported to induce a variety of adverse effects $[98,99]$. 18 $\beta$-Glycyrrhetinic acid (18 $\beta-\mathrm{GA})$ is one of the active ingredients of Glycyrrhiza glabra (Liquorice). Abd El-Twab et al. reported that 18b-GA supplementation was able to significantly upregulate the mRNA abundance of both Nrf2 and HO-1 in the kidney of MTX-treated rats [100]. 18b-GA administration was also able to downregulate levels of circulating kidney function markers, tumor necrosis factor- $\alpha$ (TNF- $\alpha$ ), kidney lipid peroxidation, and nitric oxide. This protective activity of $18 \mathrm{~b}-$ GA against MTX-induced kidney injury appeared to depend solely on activation of Nrf2 with no participation of PPAR $\gamma$ pathway [100].

Cyclophosphamide (CP) is a chemotherapeutic agent used to suppress the immune system and cancer. CPinduced ROS generation and oxidative stress have been implicated in its hepatotoxic effects [101]. Mahmoud and $\mathrm{Al}$ Dera found that $18 \beta$-GA acid was able to exert protective effects against CP-induced hepatotoxicity. They also showed that this hepatoprotective activity of $18 \beta$-GA was mediated through activation of both $\mathrm{Nrf} 2$ and PPAR $\gamma$ pathways and suppression of NF- $\kappa \mathrm{B}$ pathway [102]. More specifically, $18 \beta$-GA decreased expression levels of malondialdehyde (MDA), NF- $\kappa \mathrm{B}$, and iNOS and increased expression levels of GSH, GPX, SOD, and CAT [102].

5.5.6. (-)-Epigallocatechin-3-Gallate. (-)-Epigallocatechin-3gallate (EGCG) is a well-known green tea polyphenolic compound with an antioxidant activity. Ye et al. found that EGCG was able to ameliorate crescentic glomerulonephritis through activation of Nrf2 pathway [103]. In this study, they induced crescentic glomerulonephritis by administration of a rabbit anti-mouse glomerular basement membrane antibody. Under this condition, EGCG-treated mice showed significant reduction in phosphorylation levels of several signaling molecules such as AKT, c-Jun N-terminal kinase (JNK), extracellular signal-regulated kinase (ERK), and p38. EGCG administration also induced a marked increase in the levels of Nrf2, GCL, GPX-1, NQO-1, PPAR $\gamma$, and silent information regulator 2 (Sir2) protein 1 (SIRT1) in the kidney tissue [103]. All these transcriptional changes induced by activation of both Nrf2 and PPAR $\gamma$ pathways seemed to contribute to amelioration of crescentic glomerulonephritis induced by a glomerular basement membrane antibody.

5.5.7. Mangiferin. Mangiferin is a naturally occurring glucosylxanthone xanthonoid from Mangifera indica. MahmoudAwny et al. found that mangiferin was able to mitigate gastric ulcer in ischemia/reperfused rats. They also found that mangiferin was able to exert its gastroprotective effect via inducing the expression of Nrf2, HO-1, and PPAR $\gamma$ along with downregulating that of NF- $\kappa \mathrm{B}$ [104]. The effect of mangiferin, especially at the high dose, exceeded that was mediated by omeprazole, a proton pump inhibitor [104].

5.5.8. 3-O-Laurylglyceryl Ascorbate. Ascorbic acid is a water-soluble vitamin with an antioxidant activity. A newly synthesized amphipathic derivative of ascorbic acid, 3-O- laurylglyceryl ascorbate, was shown to activate both Nrf2 and PPAR- $\gamma$ pathways [105]. Specifically, 3-Olaurylglyceryl ascorbate was shown to be able to upregulate the expression of mRNAs encoding PPAR- $\gamma$ and Nrf 2 and their target genes including $\gamma$-GCS, HO-1, and NQO-1 [105]. Downregulation of Nrf2 mRNA level in siPPAR $\gamma$ treated cells further supported the reciprocal positive modulation of Nrf2 and PPAR $\gamma$ pathways. In addition, the effects of 3-O-laurylglyceryl ascorbate on PPAR $\gamma$ and Nrf2 mRNA levels were reduced by PPAR $\gamma$ knock down in normal human epidermal keratinocytes [105]. This suggested that PPAR $\gamma$ played a major role for 3-O-laurylglyceryl ascorbate in inducing transcription of antioxidant genes.

5.5.9. Umbelliferone. Umbelliferone is a natural product of the coumarin family used in sunscreens. Mahmoud et al. reported that umbelliferone was able to confer a protective effect against hepatotoxicity induced by cyclophosphamide (CP), which is an anticancer and immunosuppressive drug [106]. This hepatoprotective activity of umbelliferone was shown to be mediated by upregulation of Nrf2 and PPAR $\gamma$ pathways. In this report, CP-treated rats showed significant downregulation of $\mathrm{Nrf} 2, \mathrm{HO}-1$, and PPAR $\gamma$. However, this effect was markedly reversed by umbelliferone treatment [106]. Activation of PPAR $\gamma$ also appeared to inhibit the fibrogenic response to hepatic injury and protect against CP-induced inflammation [106].

5.5.10. Graptopetalum paraguayense and Resveratrol. As previously mentioned, advanced glycation end products were generated by nonenzymatic reactions between carbohydrates and proteins and found to cause pancreatic damage and oxidative stress in hyperglycemic patients $[107,108]$. Lee et al. used carboxymethyllysine (CML) to induce pancreas dysfunction and hyperglycemia through formation of advanced glycation end products. Using this model, they found that cotreatment of Graptopetalum paraguayense (GP) and resveratrol was able to ameliorate CML-induced pancreas damage and hyperglycemia. Especially, resveratrol and ethanol extracts of GP increased insulin synthesis via upregulation of pancreatic PPAR $\gamma$ and PDX-1. Resveratrol and ethanol extracts of GP also strongly activated Nrf2 pathway including GSH and $\gamma$-GCL to attenuate oxidative stress and improve insulin sensitivity [109].

5.5.11. Cyanidin-3-Glucose and Resveratrol. Cyanidin-3-glucose $(\mathrm{C} 3 \mathrm{G})$ is a natural plant pigment with an anthocyanin structure. Serra et al. found that cotreatment of C3G and resveratrol was able to induce Nrf2 activation leading to increased HO- 1 and $\gamma$-GCL mRNA expression in human colon cancer cells [110]. Resveratrol was also able to increase nuclear levels of PPAR $\gamma$ in cytokine-stimulated cells. Based on these results, they suggested the use of polyphenols as nutraceuticals to lessen intestinal inflammation in patients with inflammatory bowel disease [110].

\section{Concluding Remarks}

In this paper, we have reviewed roles of oxidative stress in the development of human diseases, two major antioxidant 
signaling cascades such as Nrf2 and PPAR $\gamma$ pathways, their potential crosstalk against oxidative stress, and pharmacological targeting of these two pathways by various $\mathrm{Nrf} 2$ and PPAR $\gamma$ activators. Since a growing body of evidence strongly suggests existence of the intimate relationship between oxidative stress and the development of various metabolic disorders and drug-induced organ injuries, discovery of the best combination of Nrf2 and PPAR $\gamma$ activators to achieve the maximal protection against this oxidative stress will be greatly beneficial for alleviating burden of numerous patients suffering from many oxidative stress-induced diseases and side effects of anticancer drugs.

\section{Conflicts of Interest}

The author declares that there are no competing interests regarding the publication of this paper.

\section{Acknowledgments}

This work was supported by a grant of the Korean Health Technology R\&D Project, Ministry of Health \& Welfare, Republic of Korea (Grant no. HI13C1046).

\section{References}

[1] M. Hayyan, M. A. Hashim, and I. M. AlNashef, "Superoxide ion: generation and chemical implications," Chemical Reviews, vol. 116, no. 5, pp. 3029-3085, 2016.

[2] M. Kvandova, M. Majzunova, and I. Dovinova, "The role of PPARgamma in cardiovascular diseases," Physiological Research, vol. 65, Supplementum 3, pp. S343-S363, 2016.

[3] H. R. Griffiths, "ROS as signalling molecules in T cells-evidence for abnormal redox signalling in the autoimmune disease, rheumatoid arthritis," Redox Report, vol. 10, no. 6, pp. 273-280, 2005.

[4] B. D'Autreaux and M. B. Toledano, "ROS as signalling molecules: mechanisms that generate specificity in ROS homeostasis," Nature Reviews Molecular Cell Biology, vol. 8, no. 10, pp. 813-824, 2007.

[5] J. Kim and Y. S. Keum, "NRF2, a key regulator of antioxidants with two faces towards cancer," Oxidative Medicine and Cellular Longevity, vol. 2016, Article ID 2746457, 7 pages, 2016.

[6] F. L. Muller, M. S. Lustgarten, Y. Jang, A. Richardson, and H. Van Remmen, "Trends in oxidative aging theories," Free Radical Biology \& Medicine, vol. 43, no. 4, pp. 477-503, 2007.

[7] J. M. Van Raamsdonk and S. Hekimi, "Deletion of the mitochondrial superoxide dismutase sod-2 extends lifespan in Caenorhabditis elegans," PLoS Genetics, vol. 5, no. 2, article e1000361, 2009.

[8] J. M. Carney, P. E. Starke-Reed, C. N. Oliver et al., "Reversal of age-related increase in brain protein oxidation, decrease in enzyme activity, and loss in temporal and spatial memory by chronic administration of the spin-trapping compound $\mathrm{N}$ tert-butyl-alpha-phenylnitrone," Proceedings of the National Academy of Sciences of the United States of America, vol. 88, no. 9, pp. 3633-3636, 1991.

[9] E. R. Stadtman, "Protein oxidation and aging," Science, vol. 257, no. 5074, pp. 1220-1224, 1992.
[10] J. Liu, E. Head, A. M. Gharib et al., "Memory loss in old rats is associated with brain mitochondrial decay and RNA/DNA oxidation: partial reversal by feeding acetyl-L-carnitine and/ or R-alpha-lipoic acid," Proceedings of the National Academy of Sciences of the United States of America, vol. 99, no. 4, pp. 2356-2361, 2002.

[11] S. C. Gupta, D. Hevia, S. Patchva, B. Park, W. Koh, and B. B. Aggarwal, "Upsides and downsides of reactive oxygen species for cancer: the roles of reactive oxygen species in tumorigenesis, prevention, and therapy," Antioxidants \& Redox Signaling, vol. 16, no. 11, pp. 1295-1322, 2012.

[12] U. Forstermann, N. Xia, and H. Li, "Roles of vascular oxidative stress and nitric oxide in the pathogenesis of atherosclerosis," Circulation Research, vol. 120, no. 4, pp. 713-735, 2017.

[13] A. Konior, A. Schramm, M. Czesnikiewicz-Guzik, and T. J. Guzik, "NADPH oxidases in vascular pathology," Antioxidants \& Redox Signaling, vol. 20, no. 17, pp. 2794-2814, 2014.

[14] P. Newsholme, V. F. Cruzat, K. N. Keane, R. Carlessi, and P. I. d. Bittencourt Jr., "Molecular mechanisms of ROS production and oxidative stress in diabetes," The Biochemical Journal, vol. 473, no. 24, pp. 4527-4550, 2016.

[15] K. Kandola, A. Bowman, and M. A. Birch-Machin, "Oxidative stress-a key emerging impact factor in health, ageing, lifestyle and aesthetics," International Journal of Cosmetic Science, vol. 37, Supplement 2, pp. 1-8, 2015.

[16] A. G. Miranda-Diaz, L. Pazarin-Villasenor, F. G. YanowskyEscatell, and J. Andrade-Sierra, "Oxidative stress in diabetic nephropathy with early chronic kidney disease," Journal of Diabetes Research, vol. 2016, Article ID 7047238, 7 pages, 2016.

[17] J. X. Jiang and N. J. Torok, "NADPH oxidases in chronic liver diseases," Advances in Hepatology, vol. 2014, Article ID 742931, 8 pages, 2014.

[18] P. Moi, K. Chan, I. Asunis, A. Cao, and Y. W. Kan, "Isolation of NF-E2-related factor 2 (Nrf2), a NF-E2-like basic leucine zipper transcriptional activator that binds to the tandem NF-E2/AP1 repeat of the beta-globin locus control region," Proceedings of the National Academy of Sciences of the United States of America, vol. 91, no. 21, pp. 9926-9930, 1994.

[19] M. Kobayashi, L. Li, N. Iwamoto et al., "The antioxidant defense system Keap1-Nrf2 comprises a multiple sensing mechanism for responding to a wide range of chemical compounds," Molecular and Cellular Biology, vol. 29, no. 2, pp. 493-502, 2009.

[20] K. Itoh, N. Wakabayashi, Y. Katoh et al., "Keap1 represses nuclear activation of antioxidant responsive elements by Nrf2 through binding to the amino-terminal Neh2 domain," Genes \& Development, vol. 13, no. 1, pp. 76-86, 1999.

[21] A. Kobayashi, M. I. Kang, H. Okawa et al., "Oxidative stress sensor Keap1 functions as an adaptor for Cul3-based E3 ligase to regulate proteasomal degradation of Nrf2," Molecular and Cellular Biology, vol. 24, no. 16, pp. 7130-7139, 2004.

[22] A. Kobayashi, M. I. Kang, Y. Watai et al., "Oxidative and electrophilic stresses activate Nrf2 through inhibition of ubiquitination activity of Keap1," Molecular and Cellular Biology, vol. 26, no. 1, pp. 221-229, 2006.

[23] B. N. Das, Y. W. Kim, and Y. S. Keum, "Mechanisms of Nrf2/ Keap1-dependent phase II cytoprotective and detoxifying gene expression and potential cellular targets of chemopreventive isothiocyanates," Oxidative Medicine and Cellular Longevity, vol. 2013, Article ID 839409, 7 pages, 2013. 
[24] H. Y. Cho, S. P. Reddy, A. Debiase, M. Yamamoto, and S. R. Kleeberger, "Gene expression profiling of NRF2-mediated protection against oxidative injury," Free Radical Biology \& Medicine, vol. 38, no. 3, pp. 325-343, 2005.

[25] W. A. Solis, T. P. Dalton, M. Z. Dieter et al., "Glutamate-cysteine ligase modifier subunit: mouse Gclm gene structure and regulation by agents that cause oxidative stress," Biochemical Pharmacology, vol. 63, no. 9, pp. 1739-1754, 2002.

[26] R. Venugopal and A. K. Jaiswal, "Nrf1 and Nrf2 positively and c-Fos and Fral negatively regulate the human antioxidant response element-mediated expression of $\mathrm{NAD}(\mathrm{P}) \mathrm{H}:-$ quinone oxidoreductasel gene," Proceedings of the National Academy of Sciences of the United States of America, vol. 93, no. 25, pp. 14960-14965, 1996.

[27] Y. H. Jeong, J. S. Park, D. H. Kim, and H. S. Kim, "Lonchocarpine increases Nrf2/ARE-mediated antioxidant enzyme expression by modulating AMPK and MAPK signaling in brain astrocytes," Biomolecules \& Therapeutics (Seoul), vol. 24, no. 6, pp. 581-588, 2016.

[28] C. H. Jin, Y. K. So, S. N. Han, and J. B. Kim, "Isoegomaketone upregulates heme oxygenase-1 in RAW264.7 cells via ROS/ p38 MAPK/Nrf2 pathway," Biomolecules \& Therapeutics (Seoul), vol. 24, no. 5, pp. 510-516, 2016.

[29] W. Miao, L. Hu, P. J. Scrivens, and G. Batist, “Transcriptional regulation of NF-E2 p45-related factor (NRF2) expression by the aryl hydrocarbon receptor-xenobiotic response element signaling pathway: direct cross-talk between phase I and II drug-metabolizing enzymes," The Journal of Biological Chemistry, vol. 280, no. 21, pp. 20340-20348, 2005.

[30] M. Yang, Y. Yao, G. Eades, Y. Zhang, and Q. Zhou, "MiR-28 regulates Nrf2 expression through a Keap1-independent mechanism," Breast Cancer Research and Treatment, vol. 129, no. 3, pp. 983-991, 2011.

[31] G. Eades, M. Yang, Y. Yao, Y. Zhang, and Q. Zhou, "miR200a regulates Nrf2 activation by targeting Keap1 mRNA in breast cancer cells," The Journal of Biological Chemistry, vol. 286, no. 47, pp. 40725-40733, 2011.

[32] S. B. Cullinan and J. A. Diehl, "Coordination of ER and oxidative stress signaling: the PERK/Nrf2 signaling pathway," The International Journal of Biochemistry \& Cell Biology, vol. 38, no. 3, pp. 317-332, 2006.

[33] H. C. Huang, T. Nguyen, and C. B. Pickett, "Phosphorylation of Nrf2 at Ser-40 by protein kinase C regulates antioxidant response element-mediated transcription," The Journal of Biological Chemistry, vol. 277, no. 45, pp. 42769-42774, 2002.

[34] Y. Katoh, K. Itoh, E. Yoshida, M. Miyagishi, A. Fukamizu, and M. Yamamoto, "Two domains of Nrf2 cooperatively bind CBP, a CREB binding protein, and synergistically activate transcription," Genes to Cells, vol. 6, no. 10, pp. 857-868, 2001.

[35] Z. Sun, Y. E. Chin, and D. D. Zhang, "Acetylation of Nrf2 by p300/CBP augments promoter-specific DNA binding of Nrf2 during the antioxidant response," Molecular and Cellular Biology, vol. 29, no. 10, pp. 2658-2672, 2009.

[36] C. M. Clements, R. S. McNally, B. J. Conti, T. W. Mak, and J. P. Ting, "DJ-1, a cancer- and Parkinson's diseaseassociated protein, stabilizes the antioxidant transcriptional master regulator Nrf2," Proceedings of the National Academy of Sciences of the United States of America, vol. 103, no. 41, pp. 15091-15096, 2006.

[37] Y. Zheng, A. Morris, M. Sunkara, J. Layne, M. Toborek, and B. Hennig, "Epigallocatechin-gallate stimulates NF-E2- related factor and heme oxygenase- 1 via caveolin-1 displacement," The Journal of Nutritional Biochemistry, vol. 23, no. 2, pp. 163-168, 2012.

[38] W. Chen, Z. Sun, X. J. Wang et al., "Direct interaction between Nrf2 and p21(Cip1/WAF1) upregulates the Nrf2mediated antioxidant response," Molecular Cell, vol. 34, no. 6, pp. 663-673, 2009.

[39] J. D. Hayes and A. T. Dinkova-Kostova, "The Nrf2 regulatory network provides an interface between redox and intermediary metabolism," Trends in Biochemical Sciences, vol. 39, no. 4, pp. 199-218, 2014.

[40] J. N. Feige, L. Gelman, L. Michalik, B. Desvergne, and W. Wahli, "From molecular action to physiological outputs: peroxisome proliferator-activated receptors are nuclear receptors at the crossroads of key cellular functions," Progress in Lipid Research, vol. 45, no. 2, pp. 120-159, 2006.

[41] J. Berger and D. E. Moller, "The mechanisms of action of PPARs," Annual Review of Medicine, vol. 53, pp. 409-435, 2002.

[42] A. Belfiore, M. Genua, and R. Malaguarnera, "PPARgamma agonists and their effects on IGF-I receptor signaling: implications for cancer," PPAR Research, vol. 2009, Article ID 830501, 18 pages, 2009.

[43] K. R. Dunning, M. R. Anastasi, V. J. Zhang, D. L. Russell, and R. L. Robker, "Regulation of fatty acid oxidation in mouse cumulus-oocyte complexes during maturation and modulation by PPAR agonists," PLoS One, vol. 9, no. 2, article e87327, 2014.

[44] I. Rusyn, M. L. Rose, H. K. Bojes, and R. G. Thurman, "Novel role of oxidants in the molecular mechanism of action of peroxisome proliferators," Antioxidants \& Redox Signaling, vol. 2, no. 3, pp. 607-621, 2000.

[45] T. Varga, Z. Czimmerer, and L. Nagy, "PPARs are a unique set of fatty acid regulated transcription factors controlling both lipid metabolism and inflammation," Biochimica et Biophysica Acta, vol. 1812, no. 8, pp. 1007-1022, 2011.

[46] A. Y. Swati Agarwal and R. K. Chaturvedi, "Peroxisome proliferator-activated receptors (PPARs) as therapeutic target in neurodegenerative disorders," Biochemical and Biophysical Research Communications, vol. 483, no. 4, pp. 1166-1177, 2017.

[47] B. Desvergne and W. Wahli, "Peroxisome proliferatoractivated receptors: nuclear control of metabolism," Endocrine Reviews, vol. 20, no. 5, pp. 649-688, 1999.

[48] S. Polvani, M. Tarocchi, and A. Galli, "PPARgamma and oxidative stress: con(beta) catenating NRF2 and FOXO," PPAR Research, vol. 2012, Article ID 641087, 15 pages, 2012.

[49] G. Kronke, A. Kadl, E. Ikonomu et al., "Expression of heme oxygenase-1 in human vascular cells is regulated by peroxisome proliferator-activated receptors," Arteriosclerosis, Thrombosis, and Vascular Biology, vol. 27, no. 6, pp. 12761282, 2007.

[50] X. Wang, Z. Wang, J. Z. Liu et al., "Double antioxidant activities of rosiglitazone against high glucose-induced oxidative stress in hepatocyte," Toxicology in Vitro, vol. 25, no. 4, pp. 839-847, 2011.

[51] E. D. Rosen and B. M. Spiegelman, "PPARgamma: a nuclear regulator of metabolism, differentiation, and cell growth," The Journal of Biological Chemistry, vol. 276, no. 41, pp. 37731-37734, 2001. 
[52] J. R. Jones, C. Barrick, K. A. Kim et al., "Deletion of PPARgamma in adipose tissues of mice protects against high fat diet-induced obesity and insulin resistance," Proceedings of the National Academy of Sciences of the United States of America, vol. 102, no. 17, pp. 6207-6212, 2005.

[53] D. B. Savage, "PPAR gamma as a metabolic regulator: insights from genomics and pharmacology," Expert Reviews in Molecular Medicine, vol. 7, no. 1, pp. 1-16, 2005.

[54] S. M. Rangwala and M. A. Lazar, "Peroxisome proliferatoractivated receptor gamma in diabetes and metabolism," Trends in Pharmacological Sciences, vol. 25, no. 6, pp. 331336, 2004.

[55] H. P. Koeffler, "Peroxisome proliferator-activated receptor gamma and cancers," Clinical Cancer Research, vol. 9, no. 1, pp. 1-9, 2003.

[56] Y. Li, Y. Qi, T. H. Huang, J. Yamahara, and B. D. Roufogalis, "Pomegranate flower: a unique traditional antidiabetic medicine with dual PPAR-alpha/-gamma activator properties," Diabetes, Obesity \& Metabolism, vol. 10, no. 1, pp. 10-17, 2008.

[57] H. Takano and I. Komuro, "Roles of peroxisome proliferatoractivated receptor gamma in cardiovascular disease," Journal of Diabetes and Its Complications, vol. 16, no. 1, pp. 108-114, 2002.

[58] Q. Shen, C. Chitchumroonchokchai, J. L. Thomas et al., "Adipocyte reporter assays: application for identification of anti-inflammatory and antioxidant properties of mangosteen xanthones," Molecular Nutrition \& Food Research, vol. 58, no. 2, pp. 239-247, 2014.

[59] L. Dubuquoy, C. Rousseaux, X. Thuru et al., "PPARgamma as a new therapeutic target in inflammatory bowel diseases," Gut, vol. 55, no. 9, pp. 1341-1349, 2006.

[60] B. Vandewalle, E. Moerman, B. Lefebvre et al., "PPARgamma-dependent and -independent effects of rosiglitazone on lipotoxic human pancreatic islets," Biochemical and Biophysical Research Communications, vol. 366, no. 4, pp. 1096-1101, 2008.

[61] R. C. Reddy and T. J. Standiford, "Nrf2 and PPAR\{gamma\}: PPARtnering against oxidant-induced lung injury," American Journal of Respiratory and Critical Care Medicine, vol. 182, no. 2, pp. 134-135, 2010.

[62] X. Zhao, Y. Zhang, R. Strong, J. C. Grotta, and J. Aronowski, "15d-Prostaglandin J2 activates peroxisome proliferatoractivated receptor-gamma, promotes expression of catalase, and reduces inflammation, behavioral dysfunction, and neuronal loss after intracerebral hemorrhage in rats," Journal of Cerebral Blood Flow and Metabolism, vol. 26, no. 6, pp. 811-820, 2006.

[63] G. Ding, M. Fu, Q. Qin et al., "Cardiac peroxisome proliferator-activated receptor gamma is essential in protecting cardiomyocytes from oxidative damage," Cardiovascular Research, vol. 76, no. 2, pp. 269-279, 2007.

[64] J. Huang, I. Tabbi-Anneni, V. Gunda, and L. Wang, "Transcription factor Nrf2 regulates SHP and lipogenic gene expression in hepatic lipid metabolism," American Journal of Physiology - Gastrointestinal and Liver Physiology, vol. 299, no. 6, pp. G1211-G1221, 2010.

[65] H. Y. Cho, W. Gladwell, X. Wang et al., "Nrf2-regulated PPAR \{gamma\} expression is critical to protection against acute lung injury in mice," American Journal of Respiratory and Critical Care Medicine, vol. 182, no. 2, pp. 170-182, 2010.
[66] B. N. Chorley, M. R. Campbell, X. Wang et al., "Identification of novel NRF2-regulated genes by ChIP-Seq: influence on retinoid X receptor alpha," Nucleic Acids Research, vol. 40, no. 15, pp. 7416-7429, 2012.

[67] Y. Y. Wang, Y. X. Yang, H. Zhe, Z. X. He, and S. F. Zhou, "Bardoxolone methyl (CDDO-Me) as a therapeutic agent: an update on its pharmacokinetic and pharmacodynamic properties," Drug Design, Development and Therapy, vol. 8, pp. 2075-2088, 2014.

[68] B. L. Probst, I. Trevino, L. McCauley et al., "RTA 408, a novel synthetic triterpenoid with broad anticancer and antiinflammatory activity," PLoS One, vol. 10, no. 4, article e0122942, 2015.

[69] Q. Q. Wu, Y. Wang, M. Senitko et al., "Bardoxolone methyl (BARD) ameliorates ischemic AKI and increases expression of protective genes Nrf2, PPARgamma, and HO-1," American Journal of Physiology - Renal Physiology, vol. 300, no. 5, pp. F1180-F1192, 2011.

[70] D. de Zeeuw, T. Akizawa, P. Audhya et al., "Bardoxolone methyl in type 2 diabetes and stage 4 chronic kidney disease," The New England Journal of Medicine, vol. 369, no. 26, pp. 2492-2503, 2013.

[71] A. S. Jimenez-Osorio, S. Gonzalez-Reyes, and J. PedrazaChaverri, "Natural Nrf2 activators in diabetes," Clinica Chimica Acta, vol. 448, pp. 182-192, 2015.

[72] D. Olagnier, R. A. Lavergne, E. Meunier et al., "Nrf2, a PPARgamma alternative pathway to promote CD36 expression on inflammatory macrophages: implication for malaria," PLoS Pathogens, vol. 7, no. 9, article e1002254, 2011.

[73] P. N. Mimche, E. Thompson, D. Taramelli, and L. Vivas, "Curcumin enhances non-opsonic phagocytosis of Plasmodium falciparum through up-regulation of CD36 surface expression on monocytes/macrophages," The Journal of Antimicrobial Chemotherapy, vol. 67, no. 8, pp. 1895-1904, 2012.

[74] E. H. Kim and Y. J. Surh, "15-Deoxy-delta12,14-prostaglandin $\mathrm{J} 2$ as a potential endogenous regulator of redoxsensitive transcription factors," Biochemical Pharmacology, vol. 72, no. 11, pp. 1516-1528, 2006.

[75] R. E. Haskew-Layton, J. B. Payappilly, H. Xu, S. A. Bennett, and R. R. Ratan, "15-Deoxy-delta12,14-prostaglandin J2 (15d-PGJ2) protects neurons from oxidative death via an Nrf2 astrocyte-specific mechanism independent of PPARgamma," Journal of Neurochemistry, vol. 124, no. 4, pp. 536-547, 2013.

[76] P. Gong, D. Stewart, B. Hu et al., "Activation of the mouse heme oxygenase-1 gene by 15 -deoxy-delta(12,14)-prostaglandin $J(2)$ is mediated by the stress response elements and transcription factor Nrf2," Antioxidants \& Redox Signaling, vol. 4, no. 2, pp. 249-257, 2002.

[77] M. J. Gorczynski, P. K. Smitherman, T. E. Akiyama et al., "Activation of peroxisome proliferator-activated receptor gamma (PPARgamma) by nitroalkene fatty acids: importance of nitration position and degree of unsaturation," Journal of Medicinal Chemistry, vol. 52, no. 15, pp. 4631-4639, 2009.

[78] D. J. Bates, P. K. Smitherman, A. J. Townsend, S. B. King, and C. S. Morrow, "Nitroalkene fatty acids mediate activation of Nrf2/ARE-dependent and PPARgamma-dependent transcription by distinct signaling pathways and with significantly different potencies," Biochemistry, vol. 50, no. 36, pp. 7765-7773, 2011. 
[79] A. Trostchansky and H. Rubbo, "Nitrated fatty acids: mechanisms of formation, chemical characterization, and biological properties," Free Radical Biology \& Medicine, vol. 44, no. 11, pp. 1887-1896, 2008.

[80] A. T. Reddy, S. P. Lakshmi, and R. C. Reddy, "The nitrated fatty acid 10-nitro-oleate diminishes severity of LPSinduced acute lung injury in mice," $P P A R$ Research, vol. 2012, Article ID 617063, 12 pages, 2012.

[81] J. Ohsumi, S. Sakakibara, J. Yamaguchi et al., "Troglitazone prevents the inhibitory effects of inflammatory cytokines on insulin-induced adipocyte differentiation in 3T3-L1 cells," Endocrinology, vol. 135, no. 5, pp. 2279-2282, 1994.

[82] L. A. Faine, M. Rudnicki, F. A. Cesar et al., "Anti-inflammatory and antioxidant properties of a new arylidenethiazolidinedione in macrophages," Current Medicinal Chemistry, vol. 18, no. 22, pp. 3351-3360, 2011.

[83] Z. N. Liu, M. Zhao, Q. Zheng, H. Y. Zhao, W. J. Hou, and S. L. Bai, "Inhibitory effects of rosiglitazone on paraquatinduced acute lung injury in rats," Acta Pharmacologica Sinica, vol. 34, no. 10, pp. 1317-1324, 2013.

[84] P. H. Shih, S. L. Hwang, C. T. Yeh, and G. C. Yen, "Synergistic effect of cyanidin and PPAR agonist against nonalcoholic steatohepatitis-mediated oxidative stress-induced cytotoxicity through MAPK and Nrf2 transduction pathways," Journal of Agricultural and Food Chemistry, vol. 60, no. 11, pp. 29242933, 2012.

[85] X. Zhang, W. E. Zhao, L. Hu, L. Zhao, and J. Huang, "Carotenoids inhibit proliferation and regulate expression of peroxisome proliferators-activated receptor gamma (PPARgamma) in K562 cancer cells," Archives of Biochemistry and Biophysics, vol. 512, no. 1, pp. 96-106, 2011.

[86] P. J. Beisswenger, "Methylglyoxal in diabetes: link to treatment, glycaemic control and biomarkers of complications," Biochemical Society Transactions, vol. 42, no. 2, pp. 450456, 2014.

[87] W. H. Hsu, B. H. Lee, Y. Y. Chang, Y. W. Hsu, and T. M. Pan, "A novel natural Nrf2 activator with PPARgamma-agonist (monascin) attenuates the toxicity of methylglyoxal and hyperglycemia," Toxicology and Applied Pharmacology, vol. 272, no. 3, pp. 842-851, 2013.

[88] W. H. Hsu, B. H. Lee, C. H. Li, Y. W. Hsu, and T. M. Pan, "Monascin and AITC attenuate methylglyoxal-induced PPARgamma phosphorylation and degradation through inhibition of the oxidative stress/PKC pathway depending on Nrf2 activation," Journal of Agricultural and Food Chemistry, vol. 61, no. 25, pp. 5996-6006, 2013.

[89] W. H. Hsu and T. M. Pan, "Treatment of metabolic syndrome with ankaflavin, a secondary metabolite isolated from the edible fungus Monascus spp," Applied Microbiology and Biotechnology, vol. 98, no. 11, pp. 4853-4863, 2014.

[90] B. H. Lee, W. H. Hsu, Y. Y. Chang, H. F. Kuo, Y. W. Hsu, and T. M. Pan, "Ankaflavin: a natural novel PPARgamma agonist upregulates Nrf2 to attenuate methylglyoxal-induced diabetes in vivo," Free Radical Biology \& Medicine, vol. 53, no. 11, pp. 2008-2016, 2012.

[91] J. T. Kim, S. Barua, H. Kim et al., "Absorption study of genistein using solid lipid microparticles and nanoparticles: control of oral bioavailability by particle sizes," Biomolecules \& Therapeutics (Seoul), vol. 25, no. 4, pp. 452-459, 2017.

[92] T. Zhang, F. Wang, H. X. Xu et al., "Activation of nuclear factor erythroid 2-related factor 2 and PPARgamma plays a role in the genistein-mediated attenuation of oxidative stress-induced endothelial cell injury," The British Journal of Nutrition, vol. 109, no. 2, pp. 223-235, 2013.

[93] M. G. Traber and J. Atkinson, "Vitamin E, antioxidant and nothing more," Free Radical Biology \& Medicine, vol. 43, no. 1, pp. 4-15, 2007.

[94] P. Bozaykut, B. Karademir, B. Yazgan et al., "Effects of vitamin $\mathrm{E}$ on peroxisome proliferator-activated receptor gamma and nuclear factor-erythroid 2-related factor 2 in hypercholesterolemia-induced atherosclerosis," Free Radical Biology \& Medicine, vol. 70, pp. 174-181, 2014.

[95] V. Karuppagounder, S. Arumugam, R. A. Thandavarayan et al., "Naringenin ameliorates daunorubicin induced nephrotoxicity by mitigating AT1R, ERK1/2-NFkappaB p65 mediated inflammation," International Immunopharmacology, vol. 28, no. 1, pp. 154-159, 2015.

[96] V. K. Gounder, S. Arumugam, W. Arozal et al., "Olmesartan protects against oxidative stress possibly through the Nrf2 signaling pathway and inhibits inflammation in daunorubicin-induced nephrotoxicity in rats," International Immunopharmacology, vol. 18, no. 2, pp. 282-289, 2014.

[97] A. C. Le Lamer, H. Authier, I. Rouaud et al., "Protolichesterinic acid derivatives: alpha-methylene-gamma-lactones as potent dual activators of PPARgamma and Nrf2 transcriptional factors," Bioorganic \& Medicinal Chemistry Letters, vol. 24, no. 16, pp. 3819-3822, 2014.

[98] N. Scheinfeld, "Three cases of toxic skin eruptions associated with methotrexate and a compilation of methotrexateinduced skin eruptions," Dermatology Online Journal, vol. 12 , no. 7, p. 15, 2006.

[99] D. H. Solomon, J. M. Kremer, M. Fisher et al., "Comparative cancer risk associated with methotrexate, other non-biologic and biologic disease-modifying anti-rheumatic drugs," Seminars in Arthritis and Rheumatism, vol. 43, no. 4, pp. 489-497, 2014.

[100] S. M. Abd El-Twab, W. G. Hozayen, O. E. Hussein, and A. M. Mahmoud, "18beta-Glycyrrhetinic acid protects against methotrexate-induced kidney injury by up-regulating the Nrf2/ARE/HO-1 pathway and endogenous antioxidants," Renal Failure, vol. 38, no. 9, pp. 1516-1527, 2016.

[101] T. M. Motawi, N. A. Sadik, and A. Refaat, "Cytoprotective effects of DL-alpha-lipoic acid or squalene on cyclophosphamide-induced oxidative injury: an experimental study on rat myocardium, testicles and urinary bladder," Food and Chemical Toxicology, vol. 48, no. 8-9, pp. 23262336, 2010.

[102] A. M. Mahmoud and H. S. Al Dera, "18beta-Glycyrrhetinic acid exerts protective effects against cyclophosphamideinduced hepatotoxicity: potential role of PPARgamma and Nrf2 upregulation," Genes \& Nutrition, vol. 10, no. 6, p. 41, 2015.

[103] T. Ye, J. Zhen, Y. Du et al., "Green tea polyphenol (-)-epigallocatechin-3-gallate restores $\mathrm{Nrf2}$ activity and ameliorates crescentic glomerulonephritis," PLoS One, vol. 10, no. 3, article e0119543, 2015.

[104] M. Mahmoud-Awny, A. S. Attia, M. F. Abd-Ellah, and H. S. El-Abhar, "Mangiferin mitigates gastric ulcer in ischemia/ reperfused rats: involvement of PPAR-gamma, NF-kappaB and Nrf2/HO-1 signaling pathways," PLoS One, vol. 10, no. 7, article e0132497, 2015.

[105] Y. Katsuyama, T. Tsuboi, N. Taira, M. Yoshioka, and H. Masaki, "3-O-Laurylglyceryl ascorbate activates the intracellular antioxidant system through the contribution of PPAR- 
gamma and Nrf2," Journal of Dermatological Science, vol. 82, no. 3, pp. 189-196, 2016.

[106] A. M. Mahmoud, M. O. Germoush, M. F. Alotaibi, and O. E. Hussein, "Possible involvement of Nrf2 and PPARgamma up-regulation in the protective effect of umbelliferone against cyclophosphamide-induced hepatotoxicity," Biomedicine \& Pharmacotherapy, vol. 86, pp. 297-306, 2017.

[107] A. Negre-Salvayre, R. Salvayre, N. Auge, R. Pamplona, and M. Portero-Otin, "Hyperglycemia and glycation in diabetic complications," Antioxidants \& Redox Signaling, vol. 11, no. 12, pp. 3071-3109, 2009.

[108] S. Schiekofer, M. Andrassy, J. Chen et al., “Acute hyperglycemia causes intracellular formation of CML and activation of ras, p42/44 MAPK, and nuclear factor kappaB in PBMCs," Diabetes, vol. 52, no. 3, pp. 621-633, 2003.

[109] B. H. Lee, C. C. Lee, Y. H. Cheng, W. C. Chang, W. H. Hsu, and S. C. Wu, "Graptopetalum paraguayense and resveratrol ameliorates carboxymethyllysine (CML)-induced pancreas dysfunction and hyperglycemia," Food and Chemical Toxicology, vol. 62, pp. 492-498, 2013.

[110] D. Serra, L. M. Almeida, and T. C. Dinis, “Anti-inflammatory protection afforded by cyanidin-3-glucoside and resveratrol in human intestinal cells via Nrf2 and PPAR-gamma: comparison with 5-aminosalicylic acid," Chemico-Biological Interactions, vol. 260, pp. 102-109, 2016. 


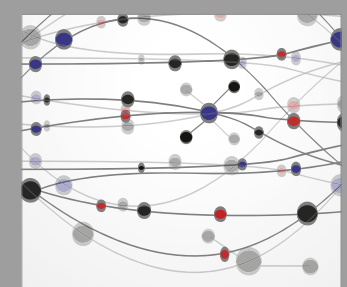

The Scientific World Journal
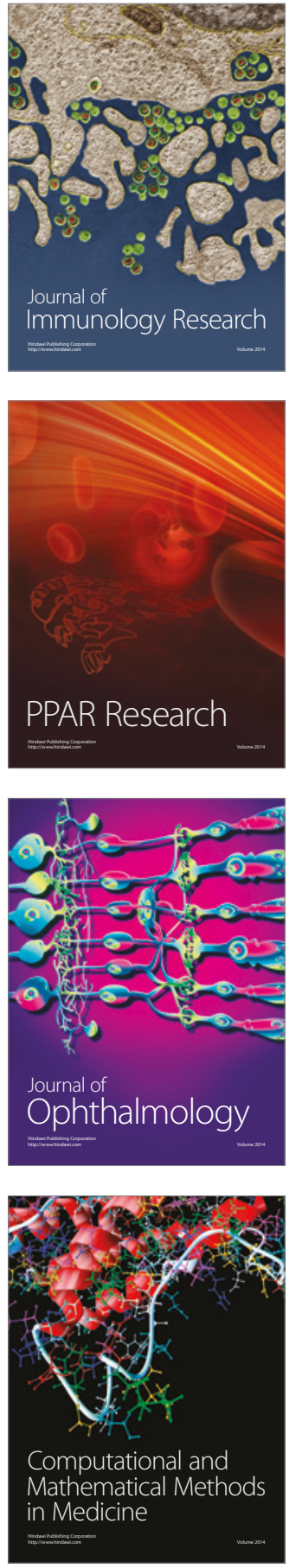

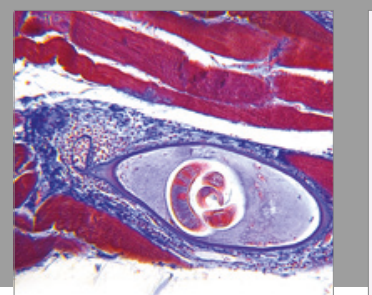

Gastroenterology Research and Practice
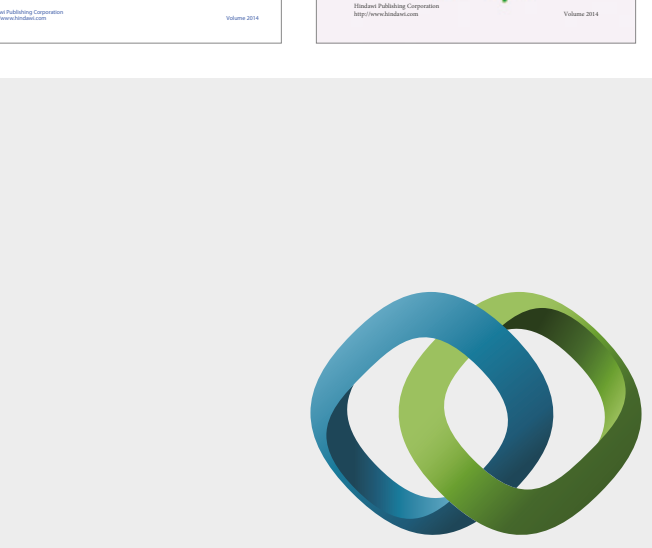

\section{Hindawi}

Submit your manuscripts at

https://www.hindawi.com
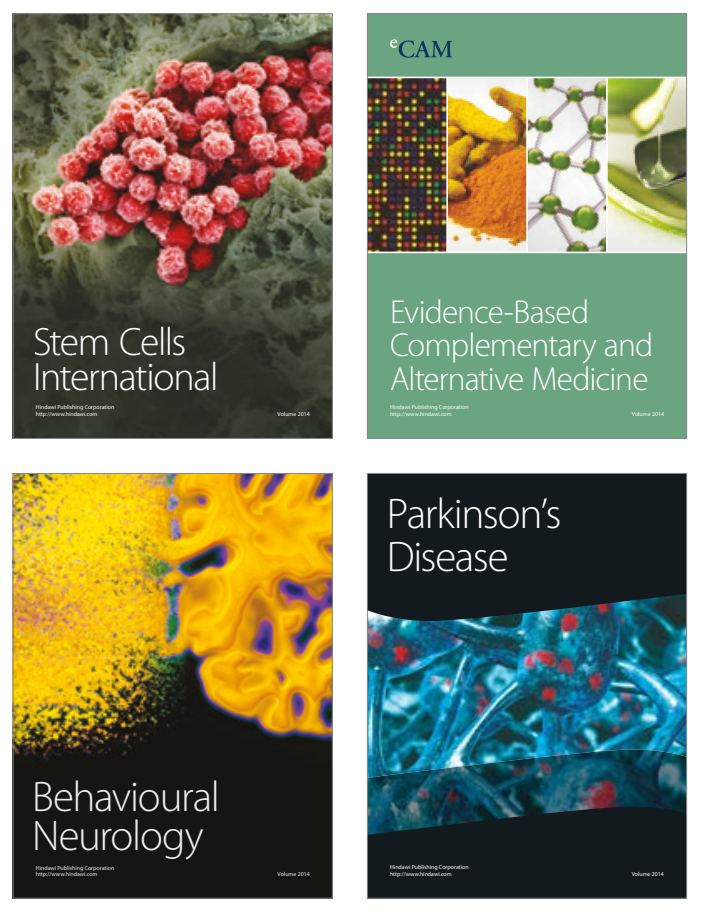
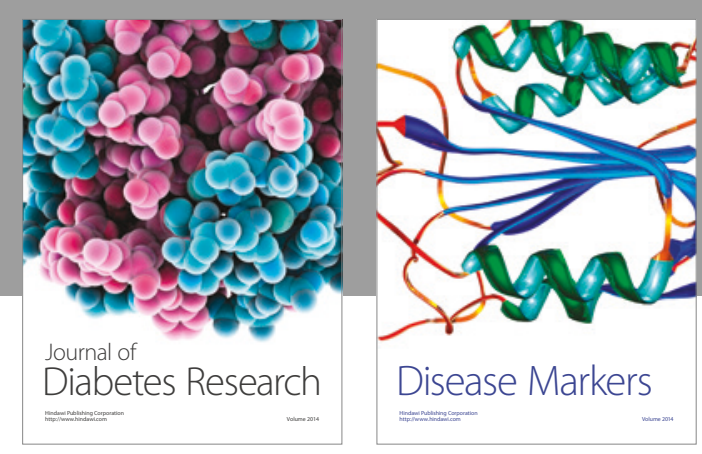

Disease Markers
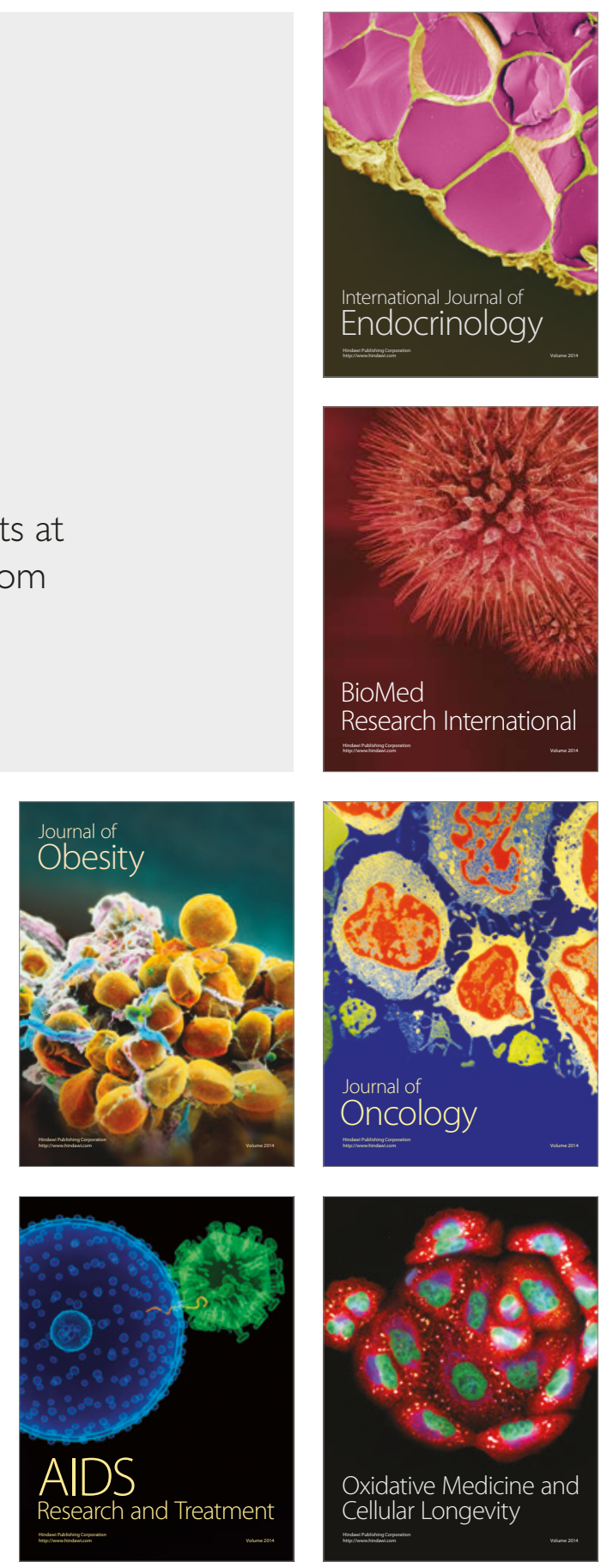